Stephen Brown*, Lara Wakeling, Mani Naiker and Sue White

\title{
Approaches to Study in Undergraduate Nursing Students in Regional Victoria, Australia
}

\begin{abstract}
In developmental research to devise a strategy to identify students who may benefit from assistance with learning habits, approaches to study were explored in undergraduate nursing students $(n=122)$ enrolled in a compulsory first-year course in physiology at a regional Australian university. The course constituted 30 credits (25\%) of their first year of study. Using the Approaches and Study Skills Inventory (ASSIST), students were identified as adopting a deep $(n=38,31 \%)$, strategic $(n=30$, $25 \%)$, or a surface $(n=54,44 \%)$ approach to study. Internal consistency (Cronbach's alpha $[\alpha]$ ) for deep, strategic, and surface was $0.85,0.87$, and 0.76 , respectively. Subsequently, a cluster analysis was done to identify two groupings: a "surface" group $(n=53)$ and a "deep/ strategic" group $(n=69)$. The surface group scored lower in deep $(33.28 \pm 6.42)$ and strategic $(39.36 \pm 6.79)$ approaches and higher in the surface $(46.96 \pm 9.57)$ approach. Conversely, the deep/strategic group scored $46.10 \pm 6.81,57.17 \pm 7.81$, and $41.87 \pm 6.47$ in deep, strategic, and surface styles, respectively. This application of the ASSIST questionnaire and cluster analysis thus differentiated students adopting a surface approach to study. This strategy may enable educators to target resources, for example additional tutorial opportunities, peerassisted study support, and tutor-led seminar sessions aimed at encouraging students to adopt a less superficial approach to study.
\end{abstract}

Keywords: undergraduate nurse education, learning styles, study skills, cluster analysis

DOI 10.1515/ijnes-2014-0020

*Corresponding author: Stephen Brown, School of Interprofessional Health Studies, Auckland University of Technology, Akoranga Drive, Auckland, New Zealand, E-mail: stbrown@aut.ac.nz Lara Wakeling, Mani Naiker, School of Health Sciences, Federation University, Ballarat, VIC, Australia, E-mail: L.wakeling@federation.edu.au, M.Naiker@federation.edu.au Sue White, School of Interprofessional Health Studies, Auckland University of Technology, Akoranga Drive, Auckland, New Zealand, E-mail: suwhite@aut.ac.nz

\section{Introduction}

Students vary in their approaches to study and in their style of learning. Throughout a course of study, a student may adopt an approach suitable for a particular situation; however, both flexibility and a willingness to adopt alternative strategies may be essential for educational achievement at university. Understanding different approaches to study adopted by students may inform pedagogical interventions aimed at enhancing student learning.

Theoretically, approaches to study have been explicated as falling within three overarching categories. A deep approach to study is characterised by a student's desire to understand, learn with meaning, and recognise underlying principles and connections amongst related principles. The deep approach is linked with a conception of learning as "transforming" and also with a preference for teaching which encourages and challenges understanding. A deep approach constructs relationships between ideas and combines additional evidence when learning new content. These processes link closely with both the intention to seek meaning and interest in ideas. We suggest that a deep approach to the study of anatomy and physiology may be the most beneficial to nursing students because the content has more relevance when applied to clinical phenomena. Also, many explanations of physiological concepts (for example, homeostatic regulation of the internal environment) require an understanding of whole body systems and the integration of knowledge of those systems in order to comprehend and address both health promotion needs and challenges to health confronted in professional practice.

A strategic approach to study is accompanied by students' close attention to details such as the structure of the content as laid out in the text, adherence to an instructor's guidelines for studying, and expected test format. Students who show a strategic approach are able to discern and utilise the aspects of a learning environment which will support their way of studying. Linkages between approach and motive are clear-cut within the strategic approach, where achievement 
motivation is strongly associated with both organised studying and time management. This approach may have the advantage of structuring knowledge for a specific purpose, for example, reciting knowledge for an exam or remembering knowledge in preparation for performing a clinical skill. However, the strategic approach may construct boundaries around knowledge which may hinder its application in novel or unfamiliar situations. Nevertheless, an undergraduate nursing student may utilise a strategic approach when time pressure requires extensive memorising of content knowledge, but may have the disadvantage of connections between facts remaining tenuous or undefined.

A surface approach to study often involves students' memorising information and doing only what is necessary to succeed on an upcoming assessment. Students with a surface approach to learning prefer teaching that transmits information and directs learning towards assessment requirements. The surface approach learner may construct syllabus boundaries, thus compartmentalising knowledge. This may lead to a lack of both understanding and purpose and promote a fear of failure. We suggest this style is the least beneficial for nursing students studying anatomy and physiology because it leads to remembering this content in isolation of its applicability to professional practice. Also, the underlying principles of physiology and associated foundation sciences (chemistry and physics) may be overwhelming for a first-year undergraduate adopting a surface approach, and we suggest that synthesis of this material with other knowledge is required to understand more complex interactions, such as physiological systems integration.

As approaches to study and learning may either enhance or undermine educational outcomes, it is important for nurse educators to be knowledgeable about their students' approaches to study and learning. Cowman (1998) and Mansouri et al. (2006) found that adoption of strategic or deep approaches to study was associated with better educational outcomes in undergraduate nurses and in first-year medical students (Mattick, Dennis, \& Bligh, 2004). Mansouri et al. (2006) also suggest that a deep or strategic approaches to study, coupled with activities which increase students' interest in the subject, may lead to improved academic outcomes. Furthermore, educators who focus on the assessment of recalled factual knowledge may induce a surface approach to study and learning, whereas those who undertake the assessment of greater understanding may encourage a deeper approach (Marton \& Säljö, 1976a).

The purpose of this developmental research was to devise a strategy to identify students who may benefit from assistance with their approaches to study. We explored the approaches to study of undergraduate nursing students at a regionally focussed university in Victoria, Australia, with the ultimate aim of illuminating how nurse educators might identify students "at risk" of less than optimal mastery of professional nursing knowledge.

\section{Literature review}

The assessment of students' approaches to study has led to the development of a number of different instruments (Tait \& Entwistle, 1996; Kolb, 1981). These include the Approaches and Study Skills Inventory for Students (ASSIST - Tait, Entwistle, \& McCune, 1997), the Visual, Aural, Read/Write, Kinaesthetic learning styles inventory (VARK - Fleming \& Mills, 1992; Alkhasawneh, Mrayyan, Docherty, Alashram, \& Yousef, 2008; Leite, Svinicki, \& Shi, 2010), the Motivated Strategies for Learning Questionnaire (MSLQ - Zeegers, 2001), and the Inventory of Learning Styles in Higher Education (ILS - Vermunt, 1994, 1998).

Each of these inventories is based on some conceptualisation of learning that can be represented in a theoretical model of learning styles. These models of learning styles are multidimensional, in that they identify a dimension along which some measure pertaining to the individual learner can be located. Dimensions may relate to personality, information processing, learning and/or studying strategies, and/or instructional preferences. For example, the sensory modalities (visual, aural, readwrite, and kinaesthetic) that a student prefers to use when internalising information is the focus of the VARK inventory. Some students prefer to use one sensory modality when internalising information (unimodal); however, the majority of people prefer to use two, three, or all four modalities (multimodal).

The Learning Styles Questionnaire is purported to measure a person's relative strengths in each of the following information processing aspects of learning style: activist, reflector, theorist, and pragmatist (Sadler-Smith, 1997). The Inventory of Learning Styles in Higher Education (ILS) was developed to inductively explore learning strategies used by students to learn at university (Vermunt, 1998), enabling users to capture descriptions of cognitive, affective, and metacognitive learning activities. By contrast, ASSIST identifies a student's characteristic orientation to studying as "deep", "surface", "strategic", "lack of direction", or "academic self-confidence", all of which logically contribute to concretely differing learning outcomes. This instrument therefore enables educators to identify students who may benefit 
from further assistance with learning habits. ASSIST for Students was developed using ideas originally proposed by Marton and Säljö (1976a, 1976b, 1997) and others (Biggs, 1987; Tait et al., 1997), combining knowledge about learning styles with descriptions of a strategic approach to studying (Entwistle \& Ramsden, 1983). ASSIST for Students thus constitutes a useful instrument for eliciting descriptive data explicating students' approach to learning and, thereby, may illuminate how students may enhance their study approaches to optimise mastery of professional nursing knowledge. The ASSIST can be used to help identify students at risk through ineffective study strategies (Tait \& Entwistle, 1996; Webster, 2002). This version of the instrument provides a clearly laid out profile of the learning approaches of each student identified via the administration of a selfreport questionnaire. Reflection and discussion of one's profile and answers to specific items contained within this instrument may raise students' awareness of their own learning styles. While students are often vaguely aware of their own "style" in comparison to those of others, illumination of specific differences may enable them to discern specifically how they might enhance their study approaches to optimise their mastery of nursing knowledge.

The learning styles of university students enrolled on health-related courses have been quantified, for example in nursing and midwifery (Wells and Higgs, 1990; Cavanagh, Hogan, \& Ramgopal, 1995; Cowman, 1998; Mansouri et al., 2006; James, D’Amore, \& Thomas, 2011; D’Amore, James, \& Mitchell, 2012), and medicine and dentistry (Newble \& Entwistle, 1986; Newble, Hejka, \& Whelan, 1990; Dobson, 2010; Samarakoon, Fernando, Rodrigo, \& Rajapakse, 2013), and other disciplines, for example engineering and chemistry (Case \& Gunstone, 2003; Lastusaari \& Murtonen, 2013; Zeegers, 2001). Cavanagh et al. (1995) used the Kolb Learning Styles Inventory to study the learning patterns of 186 nursing students and reported that the percentage of students having a predominantly concrete learning style (calculated from "accommodator" and "diverger" scores) was 53.7\%, while $46.3 \%$ was predominantly reflective (calculated from "assimilator" and "converger" scores). Cavanagh et al. (1995) also reported non-significant relations between learning style and indices such as gender, age, and educational level - suggesting that these measures may not be important in influencing learning styles for those individuals who study nursing. The same inventory was used by D'Amore et al. (2012) to study the learning patterns of 285 nursing and midwifery students in Australia. These authors described students' learning characteristics as: abstract conceptualisation, active experimentation, concrete experience, and reflective observation; and students were classified into four learning style types: converger $(n=51 ; 17.9 \%)$, diverger $(n=84 ; 29.5 \%)$, assimilator $(n=82 ; 28.8 \%)$, or accommodator $(n=68 ; 23.9 \%)$.

Cowman (1998) used a Approaches to Learning Inventory developed by Entwistle and Ramsden (1983). This was a self-reporting questionnaire containing 64 items grouped into four major scales: "meaning orientation" - (deep approach, relating ideas, use of evidence and intrinsic motivation); "reproducing orientation" (surface approach, syllabus bound, fear of failure, and improvidence); "strategic orientation" - (extrinsic motivation, strategic approach, achievement motivation); and "non-academic orientation" - (disorganised study methods, negative attitudes). This was used to investigate the learning styles of 1,005 undergraduate nursing students, during a time of curriculum change in Ireland. These researchers reported that the highest mean scores were on the scale "meaning orientation - Deep Approach" and the lowest mean scores were on the scale "strategic orientation - Strategic Approach". The "reproducing orientation - Surface Approach" scale also received a high mean score, with the sub-scale "surface approach" achieving the highest individual mean score. Using the ASSIST instrument, Mansouri et al. (2006) studied 174 baccalaureate nursing students and found that 112 (64\%) adopted a Deep approach, 39 (22\%) adopted a Surface approach, and 23 (13\%) a Strategic approach. Although fewer in total number $(n=56), 35$ midwifery students also preferred a Surface approach (63\%). Mansouri et al. (2006) also reported that nursing and midwifery students who were more interested in their fields of study tended to adopt either a deep or strategic approach to study, in preference to a surface approach, as did nursing students with a higher grade point average.

More recently, the VARK questionnaire was used by James et al. (2011) to study 334 first-year nursing and midwifery students in Australia. These researchers reported that the majority of respondents were multimodal learners, with the mean score lowest for aural, and highest for kinaesthetic learning styles. Also, there was a significant difference between the mean scores for kinaesthetic compared to visual, aural and read-write scores (James et al., 2011).

To summarise, the literature presents equivocal findings regarding dominant learning styles, and the choice of instrument to determine learning styles in undergraduate nursing students. As the ASSIST instrument measures students' characteristic study approaches that 
logically have implications for the achievement of learning outcomes, rather than students' preferred mode(s) of presentation of the content (VARK), the ASSIST was selected to identify students who may benefit from assistance with refining their learning habits.

\section{Study methods}

The study was approved by the institution's Ethics Review Committee. To identify students who may benefit from assistance with their approaches to study, we used a two-step process. First, we explored students' approaches to study using the ASSIST questionnaire. Subsequently, we used a two-step cluster analysis, an exploratory strategy designed to reveal both natural groupings (or clusters) within the data set that otherwise would not be apparent, and the importance of each input variable for the construction of a specific cluster (Kaufman \& Rousseeuw, 2005; Everitt, Landau, Leese, \& Stahl, 2011).

\section{Sample and setting}

The convenience sample was comprised of all 150 students enrolled in the first-year compulsory Anatomy and Physiology course of a Bachelor of Nursing Degree Program, a three year full-time program leading to national (Australia) registration as a nurse. The firstyear compulsory Anatomy and Physiology course was divided into two semesters, with a pass required in each semester to ensure progression into the second year of study. The course was comprised of a weekly 2 hour and 1 hour lectures (on separate days) and a weekly 1 hour tutorial. The assessment of students' mastery of course content was made by 3 short-duration progress tests at 4 week intervals (these tests were weighted at $10 \%$ of the final grade), a mid-semester test in week 6 (weighting at $40 \%$ ), and a final 2 hour examination weighted at 50\%.

\section{Instrument}

The "Approaches and Study Skills Inventory for Students ASSIST" (Tait et al., 1997) has 52 items (see Appendix) that are related to three approaches (deep, strategic, and surface) to studying and learning. The Deep and Surface subscales contained 16 items each, and the Strategic sub-scale has 20 items. Sub-scale items measured characteristics of learning approaches, as follows:

\section{Deep Approach:}

(a) Seeking meaning (items 4, 17, 30, 43);

(b) Relating ideas (items 11, 21, 33 46);

(c) Use of evidence (items 9, 23, 36, 49);

(d) Interest in ideas (items 13, 26, 39, 52);

Surface Approach:

(a) Lack of purpose (items 3, 16, 29, 42);

(b) Unrelated memorising (items 6, 19, 32, 45);

(c) Syllabus focussed (items 12, 25, 38, 51);

(d) Fear of failure (items 8, 22, 35, 48);

Strategic approach:

(a) Organised studying (items 1, 14, 27, 40);

(b) Time management (items 5, 18, 31, 44);

(c) Alertness to assessment demands (items 2, 15, 28, 41);

(d) Achieving (items 10, 24, 37, 50);

(e) Monitoring effectiveness (items 7, 20, 34, 47).

In a similar previous study (Mansouri et al., 2006), the instrument was completed by 174 nursing and 56 midwifery students, and Cronbach's $\alpha$ values for deep, surface, and strategic approaches to learning were reported to be $0.78,0.80$, and 0.78 , respectively.

\section{Data collection}

A research assistant without access to student assessment and grading information administered the questionnaire to all students enrolled in the course in week 8 of the 12 week course during a routine 1 hour tutorial class. Students were under no pressure to complete the questionnaire; all participation was voluntary and anonymous. There was no requirement to administer the instrument in any language other than English (the University's language of instruction was English).

\section{Data analysis}

All statistical procedures were carried out using appropriate software (IBM SPSS Statistics 19). For each completed questionnaire, the total score for the items comprising each of the sub-scales was calculated (see above) - a student's learning style was identified by the highest of the three sub-scale scores. The internal consistency of each sub-scale was calculated using Cronbach's $\alpha$.

In the two-step cluster analysis (Kaufman \& Rousseeuw, 2005; Everitt et al., 2011), the score for each sub-scale for each student was entered as an input 
variable. No a priori decisions were made regarding the number of clusters to be identified, as this technique automatically chooses the number of clusters on the basis of a statistical evaluation criterion (Bayes Information Criterion). The clusters were compared using independent $t$-tests, with significance set at the $p$ $<0.05$ level.

\section{Results}

The inventory was completed by 122 students ( $81 \%$ participation rate). The median age of the sample was 28 years (range 18-55 years) and $85 \%$ was female. Participants were predominantly Caucasian (approximately 90\%), the remainder being Asian or Black African. Although prior level of education was not recorded, all students had achieved entry level academic standards required for the Bachelor of Nursing degree and literacy in English. The university in which the sample was recruited traditionally attracted students from the local region (semi-rural and non-metropolis). Also, the University was considered a popular choice for students entering higher education where the family had no previous history of engagement with the University sector.

The number (\%) of students identified as adopting a deep, strategic, or surface approach was $38(31 \%)$, 30 (25\%), and 54 (44\%), respectively. Cronbach's $\alpha$ (a measure of internal consistency) was calculated for each scale. As shown in Table 1, each scale had a high degree of internal consistency, with all $\alpha$ values $>0.75$.

Table 1 Mean (SD) ASSIST “Approaches to learning” sub-scale scores of 122 undergraduate nursing students

\begin{tabular}{lccc}
\hline & Deep & Strategic & Surface \\
\hline Mean (SD) & $40.5(9.2)$ & $49.4(11.5)$ & $44.1(8.3)$ \\
Cronbach's $\alpha$ & 0.85 & 0.87 & 0.76 \\
\hline
\end{tabular}

Two clusters or groupings of students by learning approaches were identified (see Figure 1), namely a "Surface" cluster $(n=53)$ and a "Deep/Strategic" cluster $(n=69)$. The importance of inputs was the same for both clusters, with the highest importance placed on the Strategic score and the lowest importance placed on the Surface score. As the membership of a cluster was dependent on three inputs, each input was ranked in order of importance - this means that belonging to a cluster was more strongly based on an input with higher importance and less strongly based on the input with the lowest importance. The cluster comparisons presented in Figure 1 indicate the position of the input median, upper, and lower quartiles of the input for the cluster (point and whiskers) relative to the entire group median and upper and lower quartiles for that input. As illustrated in Figure 1, the Surface learners generally scored lower than the full group on both the strategic and deep sub-scales, with median scores outside the full group's lower quartiles for each input. The Deep/Strategic learners' (cluster 2) median score for the Strategic and Deep sub-scales was above the full group median values, but within the upper quartile range. For each cluster, the median surface sub-scale score was between the full group median and upper quartile score (Cluster 1) and between the full group median and lower quartile score (Cluster 2).

Independent $t$-test comparisons (see Table 2) indicate that Cluster 1 (Surface Learners) had significantly lower scores for both Deep and Strategic sub-scales and a significantly higher score for the Surface sub-scale compared to Cluster 2 (Deep/Strategic).

\section{Discussion}

This developmental research presents a strategy for identifying students who may benefit from assistance with refining their approaches to learning. An established 52 item inventory was used to identify three approaches: deep, strategic, and surface. Uniquely, we used a cluster analysis to identify two groupings within the data, using student scores for each of the three approaches as inputs. Results reveal the potential of this technique for identifying students who adopt a surface approach to study, thereby enabling educators to preferentially target resources at these students.

Fifty four (44\%) of the 122 first-year students in the convenience sample were categorised as surface learners. This contrasts with only $27 \%$ of the first-year nurses in the Mansouri et al. (2006) study. Thirty-one per cent of the students in this study were categorised as deep learners, whereas $58 \%$ of first-year student nurses were categorised as deep learners in research by Mansouri et al. (2006). Mansouri et al. (2006) also reported that nursing students' year of study was independent of the chosen approach to study and learning; that is, a student's stage of study (first, second, or third year) was not correlated to the adoption of a surface or deep learning approach. However, a higher, although not statistically significant, percentage of nursing students adopted a strategic approach as their year of 


\begin{tabular}{|c|c|c|}
\hline Cluster & 1 & 2 \\
\hline Label & Surface & Deep/Strategic \\
\hline Description & $\begin{array}{l}\text { Approach to } \\
\text { study which is } \\
\text { superficial }\end{array}$ & $\begin{array}{l}\text { Approach to } \\
\text { study to find } \\
\text { links and } \\
\text { improve } \\
\text { understanding }\end{array}$ \\
\hline Size & \begin{tabular}{|r|r|}
$43.4 \%$ \\
$(53)$
\end{tabular} & $\begin{array}{r}56.6 \% \\
(69)\end{array}$ \\
\hline \multirow[t]{3}{*}{ Inputs } & $\begin{array}{c}\text { Strategic } \\
39.36\end{array}$ & $\begin{array}{l}\text { Strategic } \\
57.17\end{array}$ \\
\hline & $\begin{array}{l}\text { Deep } \\
33.28\end{array}$ & $\begin{array}{l}\text { Deep } \\
46.10\end{array}$ \\
\hline & $\begin{array}{c}\text { Surface } \\
46.96\end{array}$ & $\begin{array}{l}\text { Surface } \\
41.87\end{array}$ \\
\hline
\end{tabular}

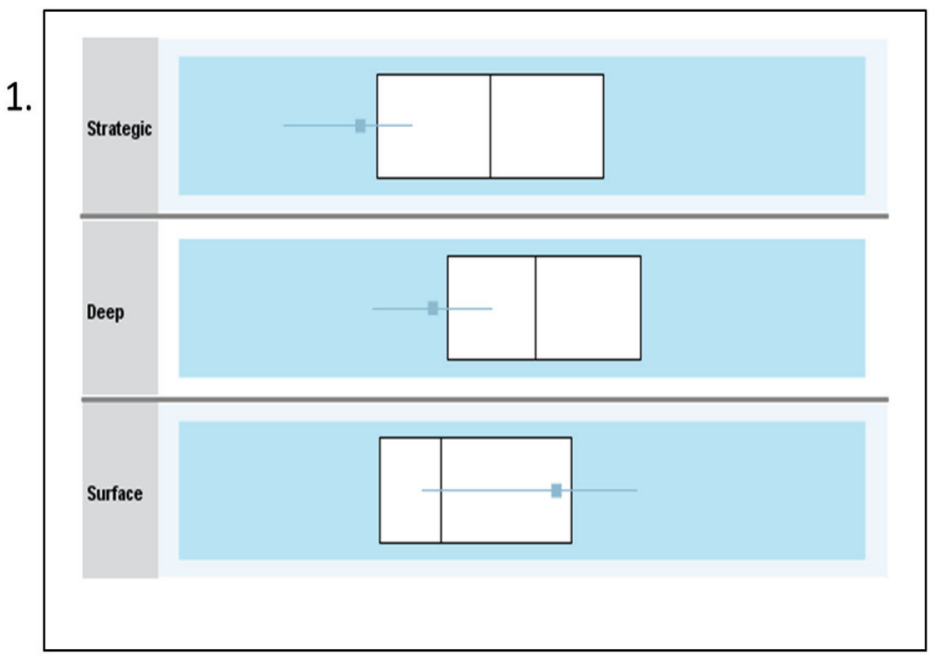

2.

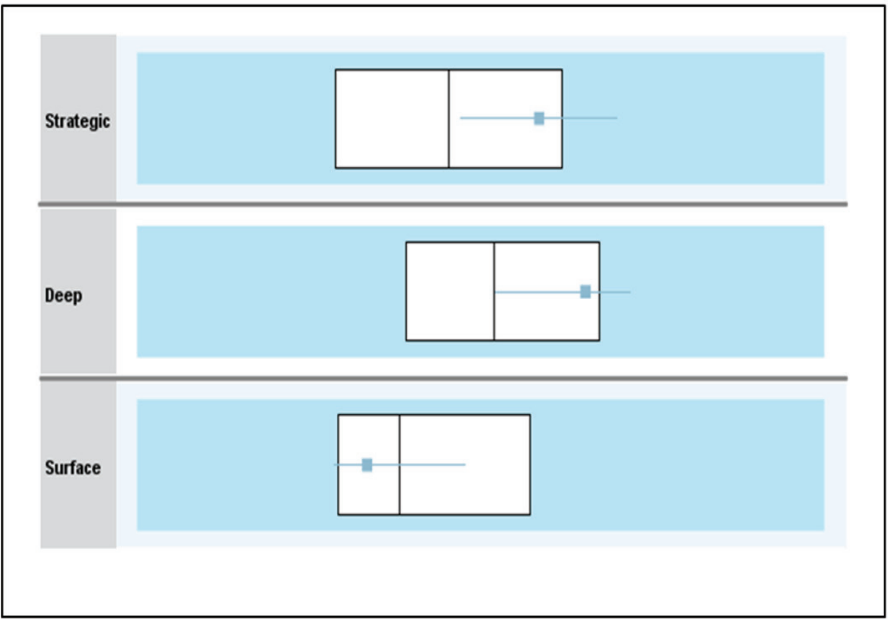

Figure 1 Cluster structure and comparison between the two clusters of undergraduate nursing students: 1. "Surface" learners; 2. "Deep/ Strategic" learners

Table 2 Independent $t$-test comparisons of the two clusters

\begin{tabular}{lccc}
\hline Cluster & $\begin{array}{c}\mathbf{1}(\boldsymbol{n}=\mathbf{5 3}) \\
\text { "Surface" } \\
\text { Mean (SD) }\end{array}$ & $\begin{array}{r}\mathbf{2}(\boldsymbol{n}=\mathbf{6 9 )} \\
\text { "Deep/Strategic" } \\
\text { Mean (SD) }\end{array}$ \\
\hline Deep & 33.28 & 46.10 & $t=-10.65$ \\
Strategic & $(6.42)$ & $(6.81)$ & $p<0.001$ \\
& 39.36 & 57.17 & $t=-13.45$ \\
& $(6.79)$ & $(7.81)$ & $p<0.001$ \\
Surface & 46.96 & 41.87 & $t=3.33$ \\
\hline
\end{tabular}

study increased - this finding may reflect more effective learning patterns that have been developed over time, or alternatively, less time for study in the later years of a program. For midwifery students, adoption of a deep or strategic approach was not affected by year of study; however, in later years of study, these students tended to adopt less of a surface approach, although this result also was not statistically significant.

Others (Snelgrove \& Slater, 2003; Snelgrove, 2004) have studied deep, surface, and "achieving” learning styles in undergraduate student nurses enrolled in either a degree or diploma course, but have not identified differences between the scores for each style, and only weak correlations between learning style and academic achievement (Snelgrove, 2004). Cowman (1998) reported mean scores for deep, strategic, and surface of 44.56, 26.77, and 42.21, respectively, in undergraduate nursing students, indicating that the strategic approach was the least preferred style adopted by these students. Others (Samarakoon et al., 2013) have reported higher mean scores for each approach achieved by medical students in pre-clinical courses (deep $=57$; surface $=51$; strategic $=69$ ), clinical courses (deep $=57$; surface $=66$; strategic $=66)$, and post-graduate courses $(\operatorname{deep}=61$; 
surface $=50$; strategic $=74$ ). As our study sample was predominantly female ( $>80 \%)$, and a mixture of students whose status was "mature entry" and "school-leaver entry" into university, comparison with these and other study findings, for example, studies of students in medicine and dentistry, may be of limited value because of differing demographics. Nevertheless, the findings of our study suggest that the prevalence of a surface approach to study may be a relevant concern amongst nurse educators.

The two-step cluster analysis elicited a model that was a fair to good fit, based on a 0.5 silhouette measure of cohesion and separation, and cluster centroids that were significantly different for all three sub-scale scores. This analysis strategy allowed those students who adopt a surface approach to study to be identified early in their undergraduate education. Thus, the strategy may facilitate more strategic allocation of resources to students who may benefit from assistance with learning habits. For example, academic programs may direct additional tutorial opportunities, mentoring, peer-assisted study support, tutor-led seminar sessions, and/or discussion groups designed to enhance learning skills toward those students identified as surface learners. It is important to note, however, that learning outcomes indicating actual student mastery of nursing knowledge were not measured in this study. Hence, the notion that moving learners from a predominant surface approach to a deep approach will facilitate academic success remains speculation. The learning style of undergraduates in health science degrees (identified using VARK - Horton, Wiederman, \& Saint et al., 2012) was not correlated with performance. Therefore, in our continuing research we seek the data required to identify any association between the approach to study and academic achievement in undergraduate nursing students.

\section{Implications for nurse educators}

Identifying surface learners at an early stage in students' undergraduate education is an important step in effectively targeting educational resources aimed at enhancing students' learning habits, and ultimately, academic outcomes. Emphasising how the content of courses (particularly more foundational courses such as anatomy and physiology) relates to the professional practice of nursing may help to promote deep/strategic approaches to learning. Such understanding might easily and inexpensively be promoted by having post-graduate nursing students or qualified registered nurses highlight the benefits of persisting with anatomy and physiology. Didactic lectures traditionally provided to large student groups in first-year curricula could be changed to more engaging and interactive smallgroup teaching/learning discussions led by peers and student tutors. We speculate that providing examples of the application of knowledge in physiology, and how this application directly impacts on patient care, may foster a greater interest in the subject content and, in turn, promote an interest in deeper learning of this content.

In this study, we deliberately targeted undergraduate nursing students enrolled in a compulsory anatomy and physiology course in their first semester of their first year of study. The course received additional institutional funding to help achieve satisfactory successful completion rates. This additional support was in the form of Peer-Assisted Student Support (PASS), a strategy in which high achieving students who had successfully completed the course in the previous year supervised additional "drop-in" sessions to provide repeat instruction in the content of the course. Thus, the institution already acknowledged the need for additional support for these students. However, attendance at the PASS sessions was voluntary and may not have been utilised by the students at most risk of not passing the course. Hence, using the ASSIST questionnaire and cluster analysis strategy we devised could be used to identify students who might specifically benefit from this resource.

Furthermore, it should be noted that a surface approach to study, identified as the most common approach to learning amongst first-year students in this study, may undermine students' success in subsequent higher levels of university education, particularly if students who are surface learners achieve passing grades with minimum effort. Educators need to identify students' approaches to study and learning early in their undergraduate education and support this with an explanation of why adopting deep and strategic approaches is preferable. The teaching of comprehensive study skills may best be included as an essential component of the first years of nursing curricula. Educators may provide a course focussing on study skills for nursing students, identifying specific learning strategies, and techniques suitable for success in a nursing degree, and further emphasising approaches appropriate for optimising learning from any specific course.

\section{Limitations of the current study}

This study used a self-report instrument (ASSIST) and convenience sampling, thereby limiting the generalisability 
of results. Also, we relied on previous analysis of the ASSIST to determine the sub-scales contained within the ASSIST instrument (deep, surface, and strategic sub-scales) and have assumed the conceptual appropriateness of this structure for our study sample. In the cluster analysis, data inputs were the scores for each identified learning style, and we have assumed that the two-step cluster analysis could discern inherent groupings based on these three inputs.

Nurse educators, including both curriculum planners and implementers, have much to gain from awareness of the different approaches to study and other factors which influence a student's approach to learning. Students' approaches to study are influenced by numerous factors, including curriculum content, modes of course delivery, lecturing styles, and assessment methods. Teaching methods, the degree of enthusiasm and commitment of educators, as well as the structure, pace and level at which information is delivered influence students' approaches to study and learning. Moreover, students' perceptions of the relevance of the content and the amount of factual knowledge required to be studied, further influence their approach to study and learning. We suggest that both student and educator awareness of different approaches to study should be incorporated within the development and delivery of curricula. We also suggest that using the
ASSIST instrument to identify deep, strategic, and surface approaches (at appropriate intervals in a course of study, for example, at the start of each semester) may be a suitable way to increase the awareness of different approaches and encourage a deeper approach to study.

\section{Conclusion}

Approaches to study were explored in undergraduate nursing students using the ASSIST for Students. Students were identified as adopting a deep (31\%), strategic $(25 \%)$, or a surface $(44 \%)$ approach to study. Further, a two-step cluster analysis identified two groupings of learners: a "surface" group (43\%) and a "deep/ strategic" group (57\%). These two techniques clearly pinpointed students adopting a surface approach to study. We suggest that nurse educators need to be knowledgeable about students' approaches to study and learning, as this may help in the allocation of resources to assist students to refine their learning habits. Regular assessment of students' approaches to learning may also guide curriculum planners in their consideration and integration of curriculum strategies which encourage deep learning.

\section{Appendix: items from the inventory indicating deep, surface, and strategic approaches to study and learning}

Deep approach (16 items)

4. I usually set out to understand for myself the meaning of what we have to learn

9. I look at the evidence carefully and try to reach my own conclusion about what l'm studying

11. I try to relate ideas I come across to those in other topics or other courses whenever possible

13. Regularly I find myself thinking about ideas from lectures when I'm doing other things

17. When I'm reading an article or book, I try to find out for myself exactly what the author means

21. When I'm working on a new topic, I try to see in my own mind how all the ideas fit together

23. Often I find myself questioning things I hear in lectures or read in books

26. I find that studying academic topics can be quite exciting at times

30. When I am reading I stop from time to time to reflect on what I am trying to learn from it

33. Ideas in course books or articles often set me off on long chains of thought of my own

36. When I read, I examine the details carefully to see how they fit in with what's being said

39. Some of the ideas I come across on the course I find really gripping

43. Before tackling a problem or assignment, I first try to work out what lies behind it

46. I like to play around with ideas of my own even if they don't get me very far

49. It is important for me to be able to follow the argument, or to see the reason behind things

52. I sometimes get "hooked" on academic topics and feel I would like to keep on studying them 


\section{Strategic approach (20 items)}

1. I manage to find conditions for studying which allow me to get on with my work easily

2. When working on an assignment, l'm keeping in mind how best to impress the marker

5. I organise my study time carefully to make the best use of it

7. I go over the work l've done carefully to check the reasoning and that it makes sense

10. It is important to me to feel that I'm doing as well as I really can on the courses here

14. I think I'm quite systematic and organised when it comes to revising for exams

15. I look carefully at tutors' comments on course work to see how to get higher marks next time

18. I'm pretty good at getting down to work whenever I need to

20. I think about what I want to get out of this course to keep my studying well focused

24. I feel that I'm getting on well, and this helps me put more effort into the work

27. I'm good at following up some of the reading suggested by lecturers or tutors

28. I keep in mind who is going to mark an assignment and what they're likely to be looking for

31. I work steadily through the term or semester, rather than leave it all until the last minute

34. Before starting work on an assignment or exam question, I think first how best to tackle it

37. I put a lot of effort into studying because l'm determined to do well

40. I usually plan out my week's work in advance, either on paper or in my head

41. I keep an eye open for what lecturers seem to think is important and concentrate on that

44. I generally make good use of my time during the day

47. When I have finished a piece of work, I check it through to see if it really meets the requirements

50. I don't find it at all difficult to motivate myself

\section{Surface approach (16 items)}

3. Often I find myself wondering whether the work I am doing here is really worthwhile

6. I find I have to concentrate on just memorising a good deal of what I have to learn

8. Often I feel I'm drowning in the sheer amount of material we have to cope with

12. I tend to read very little beyond what is actually required to pass

16. There's not much of the work here that I find interesting or relevant

19. Much of what l'm studying makes little sense: it's like unrelated bits and pieces

22. I often worry about whether l'll ever be able to cope with the work properly

25. I concentrate on learning just those bits of information I have to know to pass

29. When I look back, I sometimes wonder why I ever decided to come here

32. I'm not really sure what's important in lectures, so I try to get down all I can

35. I often seem to panic if I get behind with my work

38. I gear my studying closely to just what seems to be required for assignments and exams

42. I'm not really interested in this course, but I have to take it for other reasons

45. I often have trouble in making sense of the things I have to remember

48. Often I lie awake worrying about work I think I won't be able to do

51. I like to be told precisely what to do in essays or other assignments

\section{References}

Alkhasawneh, I. M., Mrayyan, M. T., Docherty, C., Alashram, S., \& Yousef, H. Y. (2008). Problem based learning (PBL): Assessing students' learning preferences using VARK. Nurse Education Today, 28(5), 572-579.

Biggs, J. (1987). The Study Process Questionnaire (SPQ): Manual. Hawthorn, VIC: Australian Council for Educational Research.

Case, J. M., \& Gunstone, R. F. (2003). Approaches to learning in a second year chemical engineering course. International Journal of Science Education, 25, 801-819.

Cavanagh, S. J., Hogan, K., \& Ramgopal, T. (1995). The assessment of student nurse learning styles using the Kolb Learning Styles Inventory. Nurse Education Today, 15, 177-183.
Cowman, S. (1998). The approaches to learning of student nurses in the Republic of Ireland and Northern Ireland. Journal of Advanced Nursing, 28(4), 899-910.

D’Amore, A., James, S., \& Mitchell, E. K. (2012). Learning styles of first-year undergraduate nursing and midwifery students: $A$ cross-sectional survey utilising the Kolb Learning Style Inventory. Nurse Education Today, 32(5), 506-515.

Dobson, J. (2010). A comparison between learning style preferences and sex, status, and course performance. Advances in Physiology Education, 34, 197-204.

Entwistle, N. J., \& Ramsden, P. (1983). Understanding student learning. London: Croom Helm.

Everitt, B. S., Landau, S., Leese, M., \& Stahl, D. (2011). Cluster analysis (5th ed.). Chichester: John Wiley \& Sons. 
Fleming, N. D., \& Mills, C. (1992). Not another inventory, rather a catalyst for reflection. To Improve the Academy, 11, 137-143.

Horton, D. M., Wiederman, S. D., \& Saint, D. A. (2012). Assessment outcome is weakly correlated with lecture attendance: Influence of learning style and use of alternative materials. Advances in Physiology Education, 36, 108-115.

James, S., D’Amore A., \& Thomas, T. (2011). Learning preferences of first year nursing and midwifery students: Utilising VARK. Nurse Education Today, 31(4), 417-423.

Kaufman, L., \& Rousseeuw, P. J. (2005). Finding groups in data: An introduction to cluster analysis. Hoboken, NY: Wiley.

Kolb, D. A. (1981). Learning styles and disciplinary differences. In A. W. Chickering (Ed.), The Modern American College: Responding to the new realities of diverse students and a changing society. San Francisco, CA: Jossey-Bass, 232-255.

Lastusaari, M., \& Murtonen, M. (2013). University chemistry students' learning approaches and willingness to change major. Chemistry Education Research and Practice, 14, 496-506.

Leite, W., Svinicki, M., \& Shi, Y. (2010). Attempted validation of the scores of the VARK: Learning styles inventory with multitrait multimethod confirmatory factor analysis models. Educational and Psychological Measurement, 70(2), 323-329.

Mansouri, P., Soltani, F., Rahemi, S., Nasab, M. M., Ayatollahi, A.R., \& Nekooeian, A. A. (2006). Nursing and midwifery students' approaches to study and learning. Journal of Advanced Nursing, 54(3), 351-358.

Marton, F., \& Säljö, R. (1976a). On qualitative differences in learning. I. Outcome and process. British Journal of Educational Psychology, 46, 4-11.

Marton, F., \& Säljö R. (1976b). On qualitative differences in learning: II Outcomes as a function of the learners' conception of the task. British Journal of Educational Psychology, 46, 115-127.

Marton, F., \& Säljö, R. (1997). Approaches to learning. In F. Marton, D. J. Hounsell, \& N. J. Entwistle (Eds.), The experience of learning (2nd ed.). Edinburgh: Scottish Academic Press, 36-55.

Mattick, K., Dennis, I., \& Bligh, J. (2004). Approaches to learning and studying in medical students: Validation of a revised inventory and its relation to student characteristics and performance. Medical Education, 38, 535-543.
Newble, D. I., \& Entwistle N. J. (1986). Learning style and approaches: Implication for medical education. Medical Education, 20, 162-175.

Newble, D. I., Hejka, E. J., \& Whelan, G. (1990). The approaches to learning of specialist physicians. Medial Education, 24, 101-109.

Sadler-Smith, E. (1997). Learning style: Frameworks and instruments. Educational Psychology, 17, 1-2.

Samarakoon, L., Fernando, T., Rodrigo, C., \& Rajapakse, S. (2013). Learning styles and approaches to learning among medical undergraduates and postgraduates. BMC Medical Education, 13, 42. Retrieved from http://www.biomedcentral.com/ $1472-6920 / 13 / 42$

Snelgrove, S. R. (2004). Approaches to learning of student nurses. Nurse Education Today, 24, 605-614.

Snelgrove, S., \& Slater, J. (2003). Approaches to learning: Psychometric testing of a Study Process Questionnaire. Journal of Advanced Nursing, 43(5), 496-505.

Tait, H., \& Entwistle, N. J. (1996). Identifying students at risk through ineffective study strategies. Higher Education, 31, 99-118.

Tait, H., Entwistle, N., \& McCune, V. (1997). ASSIST: A reconceptualization of the approaches to studying inventory. In C. Rust (Ed.), Improving student learning: Improving students as learners. Oxford: The Oxford Centre for Staff and Learning Development, 262-271.

Vermunt, J. D. (1994). Inventory of learning styles (ILS) in higher education. Tilburg: Tilburg University, Department of Educational Psychology.

Vermunt, J. D. (1998). The regulation of constructive learning procesesses. The British Journal of Educational Psychology, 68, 149-171.

Webster, R. (2002). Learning styles and design: The use of ASSIST for reflection and assessment. In Quality Conversations, Proceedings of the 25th HERDSA Annual Conference, Perth, Western Australia, 7-10 July 2002, p. 713.

Wells, D., \& Higgs, Z. R. (1990). Learning styles and learning preferences of first and fourth semester baccalaureate degree nursing students. Journal of Nursing Education, 29(9), 385-390.

Zeegers, P. (2001). Approaches to learning in science: A longitudinal study. British Journal of Educational Psychology, 71, 115-132. 